\title{
REVIEWS
}

\section{A Case for the Standardized Assessment of Testamentary Capacity}

Megan Brenkel ${ }^{1}$, Kimberley Whaley, LLB, LLM, TEP ${ }^{2}$, Nathan Herrmann, MD, FRCPC ${ }^{3}$, Kerri Crawford, BSc, JD², Elias Hazan ${ }^{1}$, Laura Cardiff, MA, JD² , Adrian M. Owen, $\mathrm{PhD}^{4}$, Kenneth Shulman, MD, SM, FRCPC, FRCPsych ${ }^{3}$

${ }^{I}$ Department of Psychiatry, Sunnybrook Research Institute, Toronto, ON; ${ }^{2}$ WEL Partners, Toronto, ON; ${ }^{3}$ Department of Psychiatry, Sunnybrook Health Sciences Centre, Faculty of Medicine, University of Toronto, Toronto, ON; ${ }^{4}$ The Brain and Mind Institute, Department of Psychology, Faculty of Social Sciences, Western University, London, ON, Canada https://doi.org/10.5770/cgj.21.283

\begin{abstract}
\section{Background}

With an increasingly aged, frail population that holds a disproportionate amount of wealth, clinicians (especially those with expertise in older adults) may be asked with more frequency to offer a clinical opinion on testamentary capacity (TC), the mental capacity to make a will.
\end{abstract}

\section{Method}

This paper reviews the legal criteria as well as the empirical research on assessment tools for determining testamentary capacity (TC). We also review the relevance of instruments used for the assessment of other decisional capacities in order to evince the potential value of developing a standardized assessment of TC for clinician experts.

\section{Results}

The legal criteria, often referred to as a "test", for determining requisite TC (Banks v. Goodfellow) have remained much the same since 1870 with minimal clinical input and, as such, there has been little development in TC assessment instruments. Decisional instruments designed to assess Consent to Treatment may have relevance for TC.

\section{Conclusion}

We make the case for a semi-structured interview that includes standardized criteria for the legal test for TC, supplemented by a validated brief neuropsychological assessment, which together comprise a Contemporaneous Assessment Instrument (CAI) for TC.
Key words: testamentary capacity, capacity assessment, medico-legal interface, will challenges, Contemporaneous Assessment Instrument (CAI)

\section{INTRODUCTION}

The frequency of Will challenges in the 21st century is expected to increase for a number of reasons. It is well known that we are now upon the largest transfer of wealth in human history, encompassing the World War II cohort to the baby boomer generation. In the next 30 years, it is estimated that this transfer of wealth will reach over US\$6 trillion in the US and US\$830 billion in the UK. ${ }^{(1)}$ Demographic projections reveal a significant increase in the number of older adults, especially the very old, who have the highest prevalence of dementia, cognitive impairment, and associated behavioural and psychiatric disorders. ${ }^{(2)}$ The nature of families has become more complex, with increasing rates of divorce and remarriage (53\% divorce rate in the $\mathrm{US}^{(3)}$ and $42 \%$ in England and Wales ${ }^{(4)}$ ) and individuals within families living at greater geographical distance from one another. ${ }^{(2)}$

With the rise in the choice of various relationships, including blended and fractured families where there are multiple marital or common law unions; later-life partnerships; same-sex marriages; and children of multiple relationships including step-children, adopted children, and genetically procured children, the list of potential claimants to a dispute is growing. Moreover, families are not the same tight-knit units they once were. They are no longer as likely to be in the same community, town, city or even country, because of advances in communications, technology, and the global economy. These relatively recent developments form our current demographic and will inevitably result in more complicated distributions of estate assets and transfers of wealth. (5) All of these societal, demographic, and health statistics are correspondingly relevant to ascertaining requisite TC. 
Testamentary Capacity (TC) is the legal term used to describe a complex capacity that represents the required decisional understanding to make a valid Will. ${ }^{(2)}$ It is important to note that while "competency" and "capacity" are often used interchangeably, the term "capacity" is common to both clinical and estate contexts. All mental capacities are based on two underlying principles: the understanding of relevant facts and the appreciation of the reasonably foreseeable consequence of a decision.

Although a finding of testamentary capacity is ultimately determined by the courts, decisions are often informed by clinical opinion, which represents only one of several elements that factor into judicial determinations. ${ }^{(2,6,7)}$ Judicial opinion may include input from more than one clinical expert, evidence from lay witnesses, as well as the influence of legal precedent/common law, statute, and other equitable principles. It is often accepted as good practice for a lawyer to consider, with the client, the value of an expert clinical opinion in the context of a court challenge, settlement of a dispute, or where the decisional capacity of the testator is at issue. ${ }^{(8,9,10)}$ The determination is task-, situation-, and time-specific, as posited in the evolving case law. ${ }^{(11)} \mathrm{TC}$ can be assessed contemporaneously (at the time instructions are given for a Will) ${ }^{(12)}$ or retrospectively (after the death of the testator). ${ }^{(7)}$ In this paper, we focus primarily on the contemporaneous assessment of TC.

Worldwide, courts are experiencing a dramatic increase in Will and guardianship proceedings. Elder abuse - the exploitation of an older adult by strangers, family members, or friends - is likely occurring far more frequently than is reported or ever discovered. ${ }^{(13)}$ It is inevitable that physicians who deal extensively with the elderly, including geriatricians and geriatric psychiatrists, will increasingly be asked to provide an opinion on these matters. The medical profession at large and geriatric specialists in particular must prepare to assist and help inform the courts' determinations. The objective of this paper is to explore the potential value of a standardized approach to evaluating TC, which could provide a more consistent, uniform result to the assessment process. ${ }^{(14)}$ Since TC is a construct rooted in a legal, medical, and neuropsychological interface, it is best served by a collaborative approach in its assessment ${ }^{(7)}$ —hence, the interdisciplinary collaboration taken in this review.

\section{METHODS}

\section{Information Sources and Search Strategy}

Relevant research articles were identified from a systematic search of electronic data-bases. These comprised PsycInfo (1987 to May 2016) and MEDLINE (1946 to May 2016). The electronic database key search terms included: "testamentary capacity", "psychological assessment", "wills", "clinical judgment", "forensic assessment instrument or evaluation", "forensic psychology", and "sound mind and memory".

\section{Selection Process}

We researched all published studies relevant to this review. The titles and abstracts were analyzed from the 77 search results. We selected articles that described the assessment of TC in sufficient detail to permit evaluation of the guidelines and instruments available. We excluded non-English papers where a translation was unavailable. We also omitted articles about TC that did not focus on its assessment or legal criteria. After the initial screening, where we excluded duplicates and irrelevant articles, 47 articles remained. Relevant articles and books from reference lists, as well as articles that highlighted instruments for assessing other decisional capacities, were also reviewed $(\mathrm{n}=23)$.

\section{Legal Criteria for Assessing Requisite TC}

The most widely accepted criteria for ascertaining TC were determined in the English High Court in 1870 by Chief Justice Cockburn (as he then was) in Banks v. Goodfellow, ${ }^{(15)}$ which remains the leading decision to this day. ${ }^{(11)}$ The decision was a turning point in the assessment of TC as it represented a shift away from the perspective that diagnosis of a mental disorder equates to incapacity to make a valid Will. Instead, it determined that no assumption about capacity can be made from a diagnosis alone - capacity is state-dependent, not trait-dependent. ${ }^{(16)}$ The court laid out four broad criteria to determine whether a testator has the capacity to make a valid Will:

"It is essential to the exercise of such a power that a testator shall understand the nature of the act and its effects; shall understand the extent of the property of which he is disposing; shall be able to comprehend and appreciate the claims to which he ought to give effect; and, with a view to the latter object, that no disorder of the mind shall poison his affections, pervert his sense of right, or prevent the exercise of his natural faculties - that no insane delusion shall influence his will in disposing of his property and bring about a disposal of it which, if the mind had been sound, would not have been made."(15)

A recent update and modern interpretation of the Banks v. Goodfellow criteria has been proposed, based on clinical experience: ${ }^{(11)}$

"The testator must be:

1. Capable of understanding the act of making a Will and its effects;

2. Capable of understanding the nature and extent of their property relevant to the disposition;

3. Capable of evaluating the claims of those who might be expected to benefit from his estate, and able to 
demonstrate an appreciation of the nature of any significant conflict and or complexity in the context of the testator's life situation;

4. Capable of communicating a clear, consistent rationale for the distribution of their property, especially if there has been a significant departure from previously expressed wishes or prior Wills; and

5. Free of a mental disorder, including delusions, that influences the distribution of the estate."

\section{The Role of Semi-Structured Interviews in the Assessment of Capacity}

The term Forensic Assessment Instrument (FAI) has been used to describe a semi-structured interview process designed to assess a specific mental capacity. We prefer the term Contemporaneous Assessment Instrument (CAI) in place of the term FAI, as "forensic" is often associated with the criminal justice system, whereas the term CAI can be used more broadly. ACAI provides an opportunity to probe and document mental status and cognition relevant to the legal criteria for testamentary capacity. A semi-structured interview process or CAI may provide a specific and direct answer to medico-legal questions. ${ }^{(17,18)}$

Various interview guidelines have been designed for clinicians to assess capacity to consent to treatment. While mental capacities are task-specific, these guidelines can serve as a model for the development of a CAI applied to TC. The semi-structured interviews for consent to medical treatment include: The MacArthur Competence Assessment Tool for Treatment (MacCAT-T), Capacity to Consent to Treatment Instrument (CCTI), Aid to Capacity Evaluation (ACE), Assessment of Capacity to Consent to Treatment (ACCT), Competency Interview Schedule (CIS), and the Hopemont Capacity Assessment Interview (HCAI) (this interview contains two sections: the first covers medical decision-making and the second covers financial decisions). Although the HCAI includes an assessment of capacity to manage property, its main focus is medical decision-making. ${ }^{(19,20)}$

\section{DISCUSSION}

Requisite decisional capacity to consent to treatment includes a patient's cognitive and emotional ability to accept or refuse a recommended treatment or to select among treatment alternatives. Grisso, Appelbaum, and Hill-Fotouhi developed the the MacCAT-T in 1997 for use in clinical settings. ${ }^{(18,21)}$ It represents one of the most commonly used instruments for the assessment of medical decision-making and a possible gold standard for a CAI. It uses a semi-structured interview process that utilizes information (symptoms, diagnosis, and treatment needs and recommendations) from each patient's chart in order to tailor the assessment process to the patient's decision. This instrument yields separate ratings for each of the four legal criteria of decision making specific to consent to treatment: 1) understanding information relevant to their condition and the recommended treatment; 2) reasoning about the potential risks and benefits of their choices; 3 ) appreciating the nature of their situation and the consequences of their choices; and 4) expressing a choice. The ratings provide scores of decisional capacity. These identified areas are applied in conjunction with specific and individualized clinical background information in order to determine a patient's decisional capacity to consent to treatment. ${ }^{(22)}$

The MacCAT-T affords clinicians a flexible, yet structured, approach that covers a full range of abilities necessary for establishing capacity to consent and, if necessary, assists in providing reasons for the decision. The latter is useful in marginal cases of capacity, where a person's reasons may later be tested within legal proceedings. This instrument provides a structured approach to those individuals who may be unfamiliar with the process of evaluating capacity to consent to treatment. It only takes 15-20 minutes to administer, although training is required. ${ }^{(22,21)}$

\section{Guidelines for the Development of a CAI}

Appelbaum and Grisso identified four legal standards for decision-making that a capacity assessment should address. These include: the ability to communicate a choice; the ability to understand relevant information; the ability to appreciate their situation and its likely consequences; and the ability to manipulate information rationally (reasoning). The latter is particularly important as the decision-making process is what is relevant, not the actual choice.

Appelbaum and Grisso established six criteria that could inform the establishment of a capacity assessment tool pertinent to the four legal standards for decision making. ${ }^{(23)}$ These criteria include:

1. "The functions being assessed should have close conceptual relationships with the appropriate standards of competence." This means that the measurement tasks should be derived from the legal standards that a court would find most relevant.

2. "The content of the instruments should be relevant to the decision being studied" (i.e., the distribution of their estate). Since TC is task-specific, the content must be relevant to one's specific situation because "content in other domains may differ in familiarity, complexity, and the degree to which it motivates subjects to perform".

3. "The content of the instruments should be meaningful to the person being studied."

4. "Content should be sufficiently standardized that comparisons within and across research groups are possible."

5. "Measures must have objective criteria for scoring that can be applied in a reliable fashion."

6. "Instruments should be practical for use in a research setting and potentially adaptable for clinical use." 
They must be brief, administered in one setting, and not require extensive clinical training, so that they can be adapted for routine use in clinical practice.

\section{The Case for a CAI for TC}

There is no standardized tool for the clinical assessment of TC that can act as a CAI based on clear legal criteria, nor are there any cognitive or neuropsychological models. ${ }^{(24)}$ There is limited empirical research that can advance the field. A standardized capacity assessment instrument that focuses on TC and is based on empirical research could improve upon the reliability of general clinical examinations, by focusing clinical assessment on the most relevant cognitive abilities. ${ }^{(14)}$

Marson, Huthwaite and Hebert made the case for a Testamentary Capacity Instrument (TCI). ${ }^{(2)}$ They provided a brief description of their preliminary version of the TCI, which involves a guideline of questioning underlying the four legal criteria for TC as per Banks v Goodfellow (1870). (15) The purpose of the TCI is to assess TC and differentiate cognitively intact older adults from cognitively impaired older adults. The items of the TCI are administered orally or in writing and an overall performance score emerges in one of three categories: capable, marginally capable, or incapable. The performance scores can support the latter judgements for specific legal elements and overall TC. Marson and colleagues have argued for the need to further develop a standardized approach to the measurement of TC.(2)

Pamela Champine ${ }^{(25)}$ highlighted the need to develop a CAI for all testators where their capacity may be in question. Champine argued that if a testator successfully completes a CAI for TC, this provides a validation of capacity to make a Will. Conversely, very few people who lack TC would perform well on the CAI. A robust performance on a CAI, reflecting intact cognition, strongly suggests that the testator is capable. Moreover, a strong performance on a CAI could help to counter a claim of undue influence, as individuals with higher levels of cognition may be less vulnerable to influence. ${ }^{(7,21,25)}$ Therefore, a CAI could be used to validate the decisional capacity of a testator whose cognitive functioning is sufficiently strong, and who has a complicated estate and/ or family. ${ }^{(7,25)}$ The CAI could thus serve as a confirmatory tool for TC.

Champine suggested that select court decisions, including Estate of Garrett, ${ }^{(26)}$ support the utility of contemporaneous assessment. Where there was contemporaneous assessment in a Will contest, the legal determinations of TC were consistent with expert opinion in every instance. In the remaining cases, where there was no contemporaneous assessment of TC, the legal determination of TC was highly unpredictable.

Astute estate lawyers who anticipate a Will contest may consider and recommend a contemporaneous assessment as a potential pre-emptive measure. Jacoby and Steer have cited
Lord Templeman's "golden rule" of asking for contemporaneous expert assessment whenever there is a concern about capacity. ${ }^{(9,10)}$ Such an assessment could be a means of avoiding a subsequent inquiry into requisite decisional capacity after death and may prevent litigation, expense, and the potential negative impact on family relationships. ${ }^{(5,26)}$

It is important to note that a court is likely to give more weight to a contemporaneous assessment of a testator than a retrospective assessment. This is what the court opined in the recent Orfus Estate decision, ${ }^{(27)}$ where a contemporaneous assessment was conducted on the day of the execution of the Will under scrutiny. Although a retrospective assessment was completed highlighting flaws in the contemporaneous assessment, including its lack of attention to many of the criteria relevant to TC and the assessment having been conducted largely in the presence of the daughter of the testatrix, the Court did not find the medical expert's comments to be as influential as the contemporaneous assessment. Cases such as this demonstrate how powerful contemporaneous assessments can be when a court is weighing this type of evidence.

Contemporaneous assessments are clearly valuable in the context of TC, as any questions pertaining to a testator's capacity can be directly addressed by probing of legal criteria and relevant cognitive abilities. ${ }^{(11)}$ A reliable semi-structured interview or CAI that covers the legal test for TC may not only encourage individuals with a complicated estate and/or family to seek contemporaneous assessment from a medical expert or lawyer, but may also help prevent a dramatic increase in Will contests in the coming decades.

A CAI focusing on legal criteria alone, without a cognitive screening component, may not be able to withstand a legal challenge where the capacity of the testator is in question. ${ }^{(25)}$ Therefore, particularly in complex cases, a CAI should include an accompanying neuropsychological assessment. ${ }^{(19,28)}$ An empirically validated test measuring relevant neuropsychological abilities including working memory and language, as well as specific executive functions such as judgement, planning, and reasoning would provide corroboration of the testator's intact cognitive state. A brief cognitive screening tool that could supplement the legal test for TC (a semi-structured interview or CAI) would be ideal. Importantly, it would have to be interpreted within the context of the complexity of the testator's situation, as a certain level of cognitive impairment may or may not affect TC. ${ }^{(11)} \mathrm{A}$ CAI incorporating both of these elements - the legal component and a cognitive screening test-together would serve as a confirmatory tool for TC, particularly in complex scenarios where a Will contest may be anticipated.

\section{A Neuropsychological Model is Needed for TC}

A neuropsychological model includes an extensive assessment of cognitive skills and knowledge related to the specific capacity being assessed. ${ }^{(24,28)}$ A CAI should be based on a validated neuropsychological model of TC that involves the 
cognitive functions that underpin the prescribed legal elements of TC, as updated by Shulman and colleagues ${ }^{(11)}$ and summarized as follows:

1. Capable of understanding the act of making a Will and its effects:

- Semantic knowledge with regards to terms such as death, property, and inheritance; ${ }^{(24)}$

2. Capable of understanding the nature and extent of their property relevant to the disposition:

- Long-term semantic and autobiographical memory related to assets;

- Short-term episodic and working memory are necessary for more recently acquired assets and property, or if there have been changes to the estate. Ability to form working estimates of assets, and comprehension of the approximate value attached to one's estate; ; $^{(24,28)}$

3. Capable of evaluating the claims of those who might be expected to benefit from his estate, and able to demonstrate an appreciation of the nature of any significant conflict and/or complexity in the context of the testator's life situation:

- Historical and short-term episodic personal memory are required to recall nature of relationships with testator;

- Executive functions including planning and reasoning are required for distributing one's estate; ${ }^{(24)}$

4. Capable of communicating a clear, consistent rationale for the distribution of their property, especially if there has been a significant departure from previously expressed wishes or prior Wills; and

5. Free of a mental disorder, including delusions, that influences the dispositive provisions of a Will.

- Both 4 and 5 require higher order executive functions such as judgement, reasoning, planning, and the ability to connect one's beliefs and values to the disposition of assets. ${ }^{(24,28)}$

- Language (or, broadly speaking, the ability to communicate) is an important cognitive function for all legal criteria. ${ }^{(24,28)}$

\section{CONCLUSION}

A rapidly aging population, suffering from a high prevalence of age related cognitive impairment, is about to make the largest transfer of wealth in human history to increasingly complex and fragmented families. One can readily anticipate an increase in Will challenges, with an associated need for input from medical practitioners. The development of a CAI, including an assessment of the legal components of TC and a validated cognitive screening test specific to TC, could provide more reliable information for the benefit of the courts and, ultimately, for testators and their families. In concert with this development, training programs for geriatric specialists need to incorporate educational initiatives for assessing mental capacities, including the task-specific capacity for making a Will.

\section{CONFLICT OF INTEREST DISCLOSURES}

The authors declare that no conflicts of interest exist. This research received no specific grant from any funding agency in the public, commercial, or not-for-profit sectors.

\section{REFERENCES}

1. National Financial Partners Corp. Family Wealth Transfers Report [Internet]. New York: WealthX; 2016. Accessed 7 September 2016. Available from: http:/www.wealthx.com/ wp-content/uploads/2015/01/WealthX_NFP_FamilyWealth TransfersReport-2014.pdf

2. Marson DC, Huthwaite JS, Hebert K. Testamentary capacity and undue influence in the elderly: a jurisprudent therapy perspective. Law Psychol Rev. 2004;28:71-96.

3. Engel P. MAP: Divorce Rates Around The World [Internet]. Businessinsider.com. 2016. Accessed 2 September 2016. Available from: http://www.businessinsider.com/map-divorce-ratesaround-the-world-2014-5

4. The National Archives of Great Britain. What percentage of marriages end in divorce? UK Government Web Archive. Kew, UK: webarchive.nationalarchives.gov.uk; 2013. Accessed 26 August 2016. Available from: http://webarchive. nationalarchives.gov.uk/20160106011951/http://www.ons. gov.uk/ons/rel/vsob1/divorces-in-england-and-wales/2011/ sty-what-percentage-of-marriages-end-in-divorce.html

5. Whaley KA. The intersection of family law and estates law: post-mortem claims made by modern day spouses. Advocates' Quarterly. 2012;40:1-35.

6. Kennedy KM. Testamentary capacity: a practical guide to assessment of ability to make a valid will. J Forensic Leg Med. 2012;19(4):191-95.

7. Shulman KI, Cohen CA, Kirsch FC, et al. Assessment of testamentary capacity and vulnerability to undue influence. Am J Psychiatry. 2007;164(5):722-27.

8. British Columbia Law Institute. Consultation Paper on Common Law Tests of Capacity [Internet]. Vancouver, BC: British Columbia Law Institute; 2013. Accessed 2 September 2016. Available from: http://www.bcli.org/sites/default/ files/2013-02-22_BCLI_Common-Law_Tests_of_Capacity _Consultation_Paper_(FINAL).pdf

9. Jacoby R, Steer P. How to assess capacity to make a will. BMJ. 2007;335(7611):155-57.

10. Frost M, Lawson S, Jacoby R. Testamentary Capacity:Law, Practice, and Medicine. Oxford, UK: Oxford University Press; 2015.

11. Shulman KI, Himel S, Hull IM, et al. Banks v. Goodfellow 1870: time to update the test for testamentary capacity. Can Bar Rev. 2017;95(1).

12. Shulman KI, Peisah C, Jacoby R, et al. Contemporaneous assessment of testamentary capacity. Int Psychogeriatr. 2009;21(3):433-39. 
13. National Center on Elder Abuse. Fifteen Questions and Answers About Elder Abuse. Washington, DC: The Center; 2005.

14. Purser K. Assessing testamentary capacity in the 21st century: Is Banks v Goodfellow still relevant? UNSW Law Journal. 2015;38(3):854-79.

15. Banks v. Goodfellow (1870). LR5 QB, 549.

16. Peisah C, Forlenza O, Chiu E. Ethics, capacity, and decisionmaking in the practice of old age psychiatry: an emerging dialogue. Curr Opin Psychiatr. 2009;22(6):519-21.

17. Sousa LB, Simões MR, Firmino H, et al. Financial and testamentary capacity evaluations: procedures and assessment instruments underneath a functional approach. Int Psychogeriatr. 2014;26(2):217-28.

18. Sturman ED. The capacity to consent to treatment and research: a review of standardized assessment tools. Clin Psychol Rev. 2005;25(7):954-74.

19. American Bar Association Commission on Law and Aging \& American Psychological Association. Assessment of Older Adults with Diminished Capacity: a Handbook for Psychologists. Washington, DC: American Bar Association and American Psychological Association; 2008.

20. O'Connor D. Incapability Assessments: A Review of Assessment and Screening Tools [Internet]. Vancouver, BC: Public Guardian Trustee of BC; 2009. Available from: http://www.trustee.bc.ca/ documents/STA/Incapability_Assessments_Review_Assessment _Screening_Tools.pdf

21. Grisso T, Appelbaum PS, Hill-Fotouhi C. The MacCAT-T: A clinical tool to assess patients' capacities to make treatment decisions. Psych Serv. 1997;48(11):1415-19.
22. Grisso T, Appelbaum PS. MacArthur Competence Assessment Tool for Treatment (MacCAT-T). Sarasoto, FL: Professional Resource Press; 1998.

23. Appelbaum PS, Grisso T. The MacArthur Treatment Competence Study. I: Mental illness and competence to consent to treatment. Law Hum Behav. 1995;19(2):105-26.

24. Demakis G. Civil capacities in clinical neuropsychology: research findings and practical applications. Oxford, UK: Oxford University Press; 2012.

25. Champine PR. Expertise and instinct in the assessment of testamentary capacity. Vill L Rev. 2006;51(1):25-94.

26. In re Estate of Garrett, 100 S.W. 3d 72 (Ark. App. 2003). Available at: https://scholar.google.ca/scholar_case?case $=57567044$ 24806597579\&hl=en\&as_sdt=2006

27. In re Botnick et al $v$ The Samuel and Bessie Orfus Family Foundation et al. 2013 ONCA 225, 86 ETR (3d) 6. Available at: http://canlii.ca/t/fx048

28. Sullivan L. Neuropsychological assessment of mental capacity. Neuropsychol Rev. 2004;14(3):131-42.

Correspondence to: Kenneth Shulman, MD, SM, FRCPC, FRCPsych, Sunnybrook Health Sciences Centre, Department of Psychiatry, FG 08, 2075 Bayview Ave. Toronto, ON, M4N 3M5.

E-mail: ken.shulman@sunnybrook.ca 